\title{
Dominant negative mutant forms of the cAMP response element binding protein induce apoptosis and decrease the anti-apoptotic action of growth factors in human islets
}

\author{
S. A. Sarkar • J. Gunter • R. Bouchard • J. E.-B. Reusch • \\ A. Wiseman • R. G. Gill • J. C. Hutton • S. Pugazhenthi
}

Received: 12 February 2007 / Accepted: 3 April 2007 / Published online: 26 June 2007

(C) Springer-Verlag 2007

\begin{abstract}
Aims/hypothesis Transplantation of islets is a viable option for the treatment of diabetes. A significant proportion of islets is lost during isolation, storage and after transplantation as a result of apoptosis. cAMP response element binding protein (CREB) is an important cell survival factor. The aim of the present study was to determine whether preservation of CREB function is needed for survival of human islets.

Materials and methods To determine the effects of downregulation of CREB activity on beta cell apoptosis in a transplantation setting, adenoviral vectors were used to express two dominant negative mutant forms of CREB in human islets isolated from cadaveric donors. Markers of apoptosis were determined in these transduced islets under basal conditions and following treatment with growth factor.

Results Expression of CREB mutants in human islets resulted in significant $(p<0.001)$ activation of caspase-9, a
\end{abstract}

Electronic supplementary material The online version of this article (doi:10.1007/s00125-007-0707-z) contains supplementary material, which is available to authorised users.

J. Gunter J. E.-B. Reusch·S. Pugazhenthi $(\bowtie)$

Division of Endocrinology, Metabolism and Diabetes,

Department of Medicine,

University of Colorado at Denver and Health Sciences Center,

P.O. Box 6511, Mail Stop 8106, Aurora, CO 80045, USA

e-mail: subbiah.pugazhenthi@uchsc.edu

J. Gunter $\cdot$ R. Bouchard · J. E.-B. Reusch $\cdot$ S. Pugazhenthi

The Section of Endocrinology, Veterans Affairs Medical Center,

Denver, CO, USA

S. A. Sarkar · A. Wiseman • R. G. Gill • J. C. Hutton

Barbara Davis Center for Childhood Diabetes and Rocky

Mountain Islet Transplantation Program,

Aurora, CO, USA key regulatory enzyme in the mitochondrial pathway of apoptosis, when compared with islets transduced with adenoviral beta galactosidase. Immunocytochemical analysis showed the activation of caspase-9 to be predominantly in beta cells. Other definitive markers of apoptosis such as parallel activation of caspase-3, accumulation of cleaved poly-(ADP-ribose) polymerase and nuclear condensation were also observed. Furthermore, the anti-apoptotic action of growth factors exendin- 4 and betacellulin in human islets exposed to cytokines was partially lost when CREB function was impaired.

Conclusions/interpretation Our findings suggest that impairment of CREB-mediated transcription could lead to loss of islets by apoptosis with potential implications in islet transplantation as well as in the mechanism of beta cell loss leading to diabetes.

Keywords Apoptosis · Betacellulin · Caspases · cAMP response element binding protein - CREB . Cytokines · Exendin- $4 \cdot$ Human islets $\cdot$ Transplantation
Abbreviations
BTC betacellulin
CRE cAMP response element
CREB cAMP response element binding protein
DAPI 4',6-diamidino-2-phenylindole
GFP green fluorescent protein
HEK human embryonic kidney
KCREB dominant negative mutant form of CREB
IEQ islet equivalents
MCREB dominant negative mutant form of CREB
MnSOD manganese superoxide dismutase
MOI multiplicity of infection
OCT optimal cutting temperature compound
PARP poly-(ADP-ribose) polymerase 
TBST tris-buffered saline with tween-20

TUNEL terminal deoxynucleotidyl transferase-mediated dUTP-biotin nick-end labelling

\section{Introduction}

Islet transplantation is a viable option for the treatment of type 1 diabetes. Advances in transplantation techniques from several laboratories culminated in 2000 in the development of the Edmonton protocol for clinically successful islet transplantation [1]. The major limitation of this therapeutic approach is that islets from two to four cadaveric pancreases are required for insulin independence in one diabetic patient. A significant portion of the islet mass is lost during isolation, storage and after transplantation as islets are subjected to stress from multiple sources. Apoptosis is considered to be the major cause of islet loss as shown by the presence of several apoptotic markers [2, 3].

The mechanism of beta cell apoptosis in human islets isolated from cadaveric donors is not clearly understood. Apoptosis takes place during the isolation process when extracellular matrix surrounding islets is disrupted by exogenous isolation enzymes [4]. In addition, nonspecific inflammatory reaction at the site of transplantation could lead to release of proinflammatory cytokines and free radicals, potential inducers of apoptosis [2]. Intra-islet cytokine production [5] can further aggravate the apoptotic pathway. Cytokines contribute to oxidative stress through inducible nitric oxide synthase-mediated generation of nitric oxide [6]. Pancreatic beta cells are vulnerable to injury under conditions of oxidative stress since they are characterised by a significantly low-level production of antioxidant enzymes, including manganese superoxide dismutase (MnSOD), catalase and glutathione peroxidase [7].

Previous in vitro and in vivo studies have used several approaches to improve islet survival and transplantation outcomes. For example, Bertera et al. [8] showed that production of the antioxidant enzyme, MnSOD, leads to improved survival of mouse islet grafts. Overexpression of the $\mathrm{B}$ cell CLL/lymphoma 2 gene (Bcl2), an anti-apoptotic gene, resulted in significant protection against apoptosis in vivo [9]. Similar results have been obtained by transferring the insulin gene [10], anti-apoptotic gene Bcl-XL [11] and XIAP (now known as baculoviral IAP repeat-containing 4 gene [BIRC4]), an endogenous inhibitor of caspases [12]. These studies suggested that manipulation of isolated islets is a potential strategy to improve islet survival after transplantation.

It is also important to understand the beta cell survival pathways that preserve islet function. One such pathway is growth factor-mediated activation of the transcription factor cAMP response element (CRE) binding protein (CREB), which leads to the expression of genes needed for beta cell function and survival. In a recent study [13], we made two significant observations in the context of beta cell apoptosis. First, we demonstrated that cytokines decrease CREBmediated expression of the anti-apoptotic gene $B c l 2$ in MIN6 cells, a mouse beta cell line and in mouse islets. Second, we observed that overexpression of mutant forms of CREB led to the activation caspase-9, a marker for the mitochondrial pathway of apoptosis. CREB-mediated transcription is likely to be impaired after transplantation of human islets. Factors contributing to CREB downregulation in islets could be cytokines and oxidative stress. In addition, the immunosuppressive drug tacrolimus (FK506), used in patients receiving islets, has been shown to inhibit CREB-mediated transcription [14]. Under conditions of CREB downregulation, growth factors are likely to be less effective, since many of them target CREB to induce cytoprotective genes $[15,16]$.

Although recent reports $[13,17,18]$ have suggested that CREB plays a role in beta cell survival, no previous study has examined its role in the survival of human islets. The objectives of the present study were to determine the effects CREB downregulation in human islets and to examine the anti-apoptotic actions of the beta cell-specific growth factors in islets exposed to cytokines. By transduction of islets with adenoviral vectors expressing dominant negative mutant forms of CREB, we demonstrate that CREB downregulation could play a role in beta cell apoptosis in human islets in conditions leading to beta cell loss in diabetes and during islet transplantation.

\section{Materials and methods}

Materials CMRL 1066 medium (Mediatech, Hendon, VA, USA) was supplemented with human serum albumin $(0.5 \%)$, nicotinamide $(10 \mathrm{mmol} / \mathrm{l})$, and is referred to below as Miami medium. Exendin-4, betacellulin (BTC) and 4',6diamidino-2-phenylindole (DAPI) were purchased from Sigma Chemical (St Louis, Missouri, USA). Human cytokines IL-1 $\beta$ (5 U/ng), TNF- $\alpha$ (100 U/ng) and IFN- $\gamma$ (50 U/ng) were obtained from Roche Applied Science (Indianapolis, IN, USA). Antibodies specific for CREB, phospho CREB, AKT, phospho AKT, BCL2, cleaved poly(ADP-ribose) polymerase (PARP), beta galactosidase, active cleaved forms of caspase- $3,-7,-8$ and -9 and beta actin were from Cell Signaling (Beverly, MA, USA). Cy3conjugated anti rabbit IgG and FITC-conjugated antiguinea pig $\operatorname{IgG}$ were obtained from Jackson Immuno Research Laboratories (West Grove, PA, USA). The caspase-3 assay kit was purchased from Sigma Chemical and the caspase- 9 assay kit was from Chemicon International (Temecula, CA, USA). Terminal deoxynucleotidyl 
transferase-mediated dUTP-biotin nick-end labelling (TUNEL) In Situ Cell Death Detection Kit was purchased from Roche Diagnostics (Mannheim, Germany).

Preparation of recombinant adenovirus For generation of recombinant adenoviruses by homologous recombination, cDNAs encoding dominant negative mutant forms of CREB (KCREB, MCREB) were first subcloned into the plasmid pACCMVpLpA, which encodes the left end of the adenovirus chromosome containing the $E 1 A$ gene and the $5^{\prime}$ half of the $E 1 B$ gene replaced with cytomegalovirus major immediate early promoter [19]. Plasmids containing the appropriate constructs in pACCMVpLpA were co-transfected with BstBI-digested Ad5dl327 $7_{\text {Bst }} \beta$-gal-TP complex in human embryonic kidney (HEK)-293 cells by the LipofectAMINE Plus (Invitrogen, Carlsbad, CA, USA) method. After complete cytopathic effect was observed (710 days), cells were harvested, freeze-thawed to release virus and used for plaque purification as described previously [20]. Virus was propagated in HEK-293 cells and purified by $\mathrm{CsCl}$ gradient purification [21].

Isolation and adenoviral transduction of human islets $\mathrm{Hu}-$ man islets were isolated by collagenase digestion (cold ischaemia time 4-9 h) by the Islet Cell Resource Center at the University of Colorado at Denver and Health Sciences Center using the Edmonton protocol [1]. All donors were brain-dead, heart-beating individuals from the state of Colorado who had died in motor vehicle accidents. Written informed consent was obtained from next of kin of donors. None had a previous history of diabetes or inflammatory diseases. Islet purity $(65-90 \%)$ and viability $(65-85 \%)$ were determined by dithizone and Syto13/ethidium bromide staining, respectively, using standard operation procedures defined by the Clinical Islet Laboratory (SMRI, Edmonton, $\mathrm{AB}$, Canada). Islet preparations $(2,000$ islet equivalents [IEQ]) when transplanted under the kidney capsule of streptozotocin-diabetic $\mathrm{Rag}^{-/-}$B6 mice normalised hyperglycaemia, indicating long-term survival and functionality. Islets were precultured for 12 to $18 \mathrm{~h}$ in Miami medium in $5 \% \mathrm{CO}_{2}$ and $37^{\circ} \mathrm{C}$. For adenoviral transduction, islets in a small volume of $200 \mu \mathrm{l}$ medium were mixed with recombinant adenoviruses at room temperature for $1 \mathrm{~h}$ and later the islets were mixed with medium ( $3 \mathrm{ml} / 1,000$ IEQ) and incubated at $37^{\circ} \mathrm{C}$ in nontreated culture dishes.

Assay of caspase-3 and caspase-9 The activities of caspase-3 and caspase- 9 were determined using assay kits from Sigma Chemical and Chemicon International, respectively. After appropriate adenoviral transduction and treatment, islets were lysed with the lysis buffer provided in the kit and 10,600 $g$ supernatant fractions were used for the assay. The substrates for the caspase- 3 and caspase- 9 assays were $p$-nitroanilide-labelled peptides, DEVD and IETD, respectively. The released chromophore was read at $405 \mathrm{~nm}$ in a microplate reader. In addition, activation of caspases was also determined by immunoblot analysis of the cleaved active fragments of the respective enzymes.

TUNEL staining In situ detection and quantification of apoptosis was done by labelling DNA strand breaks by terminal-deoxynucleotidyl transferase enzyme, which catalyses the polymerisation of labelled nucleotides to the free $3^{\prime}$ hydroxyl end of DNA by using a TUNEL cell death detection kit according to the manufacturer's protocol. Briefly, frozen sections $(7 \mu \mathrm{m})$ were hydrated in PBS for $30 \mathrm{~min}$ and treated with freshly prepared permeabilisation solution containing $0.1 \%$ (vol./vol.) Triton X-100 in $0.1 \%$ (wt/vol.) sodium citrate ( $\mathrm{pH} \mathrm{6.0)}$ for $2 \mathrm{~min}$ on ice and rinsed twice in PBS. The slides were then incubated in labelling and enzyme solution for $60 \mathrm{~min}$ at $37^{\circ} \mathrm{C}$ in a humid chamber in the dark. The samples were then washed twice in PBS and analysed by fluorescence microscopy. Appropriate positive and negative controls were also included in the assay as suggested in the protocol.

Immunocytochemical analysis of islets After transducing the islets with adenoviral vectors and appropriate treatments, the islets were fixed in $4 \%$ (wt/vol.) paraformaldehyde solution for $15 \mathrm{~min}$, suspended in $30 \%$ (wt/vol.) sucrose solution for another $30 \mathrm{~min}$, embedded in optimal cutting temperature compound (OCT) from Tissue-Tek (Sakura Finetek USA, Torrance, CA, USA) and frozen. Immunocytochemistry was carried out with $7 \mu \mathrm{m}$ thick sections. The sections, circled with PAP pen, were incubated at $37^{\circ} \mathrm{C}$ for $10 \mathrm{~min}$ and soaked in PBS for $10 \mathrm{~min}$. The slides were heated for $5 \mathrm{~min}$ in $10 \mathrm{mmol} / 1$ citrate buffer ( $\mathrm{pH} \mathrm{6.0)}$ in a steamer and cooled for $15 \mathrm{~min}$. After washing in PBS, the slides were incubated in blocking solution (5\% normal goat serum and $0.2 \%$ [vol./vol.] Triton in PBS) for $1 \mathrm{~h}$ in humidified chamber. The slides were exposed to primary antibodies in $3 \% \mathrm{BSA}$ at $4^{\circ} \mathrm{C}$ overnight in a humidified chamber, washed in PBS and exposed to secondary antibodies linked to $\mathrm{Cy} 3$ or FITC in 3\% BSA for $1 \mathrm{~h}$ in the dark. After PBS wash, the slides were incubated with DAPI $(2 \mu \mathrm{g} / \mathrm{ml})$ for $10 \mathrm{~min}$, washed in PBS and mounted with glycerol mounting medium. The sections were examined by fluorescent microscopy using a Zeiss Axioplan 2 microscope (Carl Zeiss MicroImaging, Thornwood, NY, USA) fitted with a high-performance chargedcoupled device (Cooke SensiCam; The Cooke Corporation, Romulus, MI, USA). For quantitation, the mean integrated fluorescence intensity of the images was calculated using Slide Book Application software (Intelligent Imaging Innovations, Denver, CO, USA). 
Immunoblotting Islets incubated under appropriate conditions were washed with ice-cold PBS and cell lysates were prepared. The protein content of the lysates was measured [22]. Diluted samples containing equal amounts of protein were mixed with $2 \times$ Laemmli sample buffer. The proteins were resolved on $12 \%$ SDS-polyacrylamide gels and transferred to polyvinylidene difluoride (PVDF) membranes. The blots were blocked with Tris-buffered saline with Tween-20 (TBST; 20 mmol/l Tris-HCl [pH 7.9], 8.5\% $\mathrm{NaCl}$ [wt/vol.] and $0.1 \%$ Tween-20 [vol./vol.]) containing $5 \%$ non-fat dry milk at room temperature for $1 \mathrm{~h}$ and exposed to primary antibody in TBST containing 5.0\% BSA at $4{ }^{\circ} \mathrm{C}$ overnight. After washing with TBST, antirabbit $\operatorname{IgG}$ conjugated to alkaline phosphatase was added for $1 \mathrm{~h}$ at room temperature. Blots were then rinsed with washing buffer $(10 \mathrm{mmol} / \mathrm{l}$ Tris- $\mathrm{HCl}[\mathrm{pH} 9.5], 10 \mathrm{mmol} / \mathrm{l}$ $\mathrm{NaCl}$ and $1 \mathrm{mmol} / \mathrm{l} \mathrm{MgCl}_{2}$ ), developed with CDP-Star reagent (New England Biolabs, Beverly, MA, USA) and exposed to X-ray film. The intensity of bands was measured using Fluor-S Multilmager and Quantity One software from Bio-Rad (Hercules, CA, USA).

Statistical analysis This was performed by one-way ANOVA with Dunnett's multiple comparison test. Data are presented as means \pm SEM unless stated otherwise.

\section{Results}

Adenoviral transduction of human islets We were able to introduce genes of interest in human islets by transducing with recombinant adenoviruses at a multiplicity of infection (MOI) of 50 and 100. Immunocytochemical analysis of human islets transduced with adenoviral green fluorescent protein (GFP) showed a 30 to $55 \%$ efficiency of gene transfer (Fig. 1a). Production of beta galactosidase was demonstrated by immunofluorescent labelling and immunoblot analysis. We also verified the transfer of mutant forms of CREB, namely KCREB and MCREB. Both mutants were transduced with similar efficiency at an MOI of 50 to 100 as evaluated by western blot analysis of flag tag production for KCREB and of decreased CREB phosphorylation for MCREB, which interferes with phosphorylation/activation of endogenous CREB (Fig. 1b). The decreases were 46 and $60 \%$ at an MOI of 50 and 100 respectively (Fig. 1c).

Dominant negative mutant forms of CREB induce the mitochondrial pathway of apoptosis in human islets To determine if CREB is essential for islet survival we examined a panel of markers of apoptosis in human islets transduced with KCREB or MCREB. KCREB is mutated at
Fig. 1 Adenoviral transduction of human islets. a Human islets were transduced with adenoviral GFP or beta galactosidase (bGal; MOI 50) for $48 \mathrm{~h}$. The later set of islets was immunostained with $\mathrm{Cy} 3$ for bGal and examined by fluorescent microscopy along with GFPexpressing cells. b Human islets were transduced with recombinant adenoviruses encoding bGal, KCREB or MCREB at an MOI of 50 or 100 for $48 \mathrm{~h}$. Lysates were prepared and immunoblotted for bGal, Flag tag, PCREB, CREB or beta (b) actin respectively. A representative blot from three batches of islets is provided. c The bands were quantitated by scanning densitometry and the ratio of PCREB: CREB was determined. The results are means \pm SEM of three batches of islets. ${ }^{*} p<0.001$ vs no-virus control a

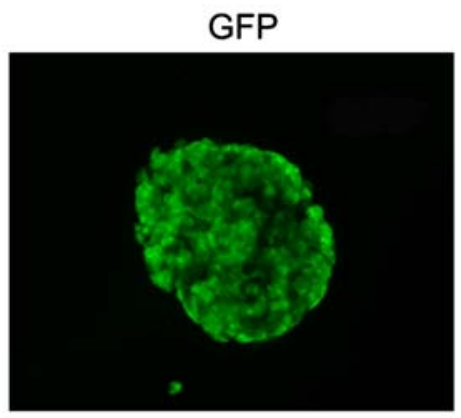

b

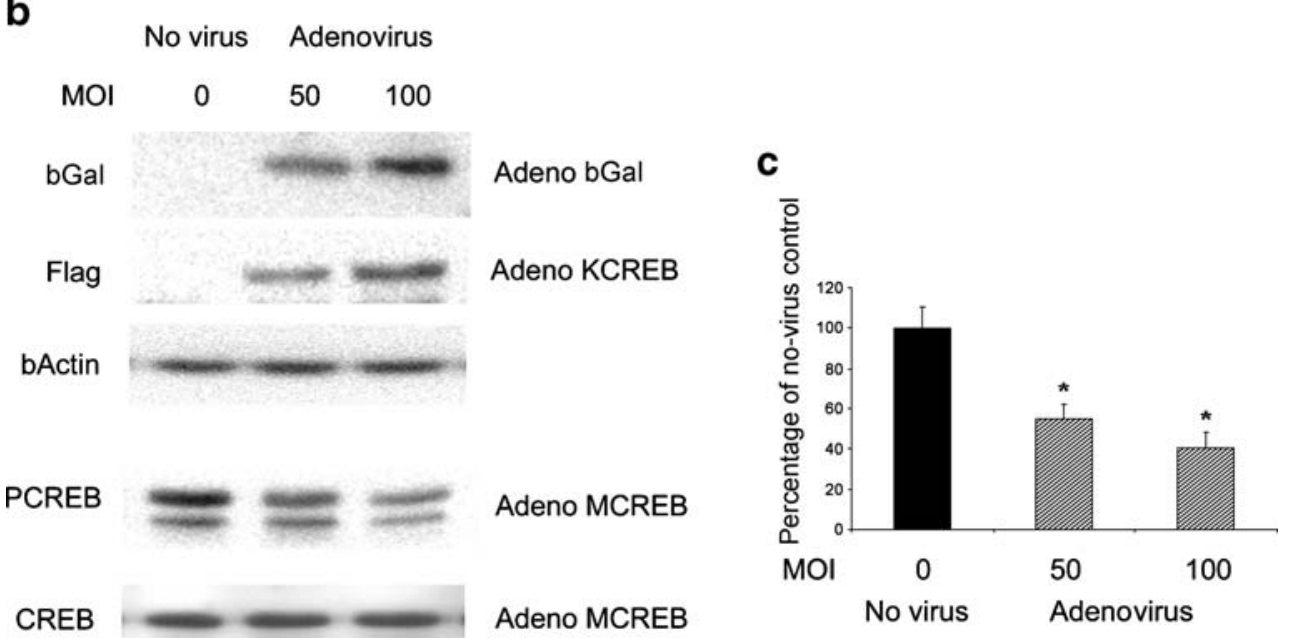


the DNA binding domain. It will heterodimerise with endogenous CREB and reduce its binding to CRE by sequestering it away from the promoter. MCREB is mutated at the phosphorylation site (S133A). Although MCREB binds to the CRE site, it cannot bind to the coactivator, CREB binding protein. Thus both mutants interfere with CREB-mediated transcription. Adenoviral beta galactosidase was used as control. We carried out immunoblot analysis of cleaved active fragment of different caspases (Fig. 2a). Some basal activation of caspases was seen in islets not exposed to adenovirus. There are mainly two pathways of apoptosis, the extrinsic death receptor pathway, which activates caspase- 8 , and the intrinsic mitochondrial pathway, which activates caspase-9. Apoptosis in isolated human islets is inevitable as they are exposed to stress from multiple sources. Apoptosis in islets

a

\begin{tabular}{lcccccccc} 
& & NV & \multicolumn{2}{c}{ bGal } & \multicolumn{2}{c}{ KCREB } & \multicolumn{2}{c}{ MCREB } \\
MOI & 0 & 50 & 100 & 50 & 100 & 50 & 100
\end{tabular}

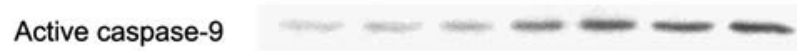

Active caspase-8

Active caspase-3

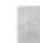

Active caspase-7

Active caspase-7

Cleaved PARP

bActin

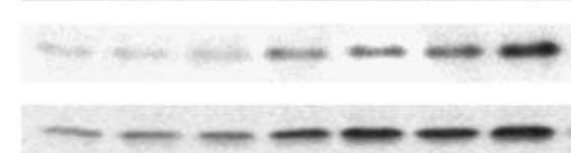

b

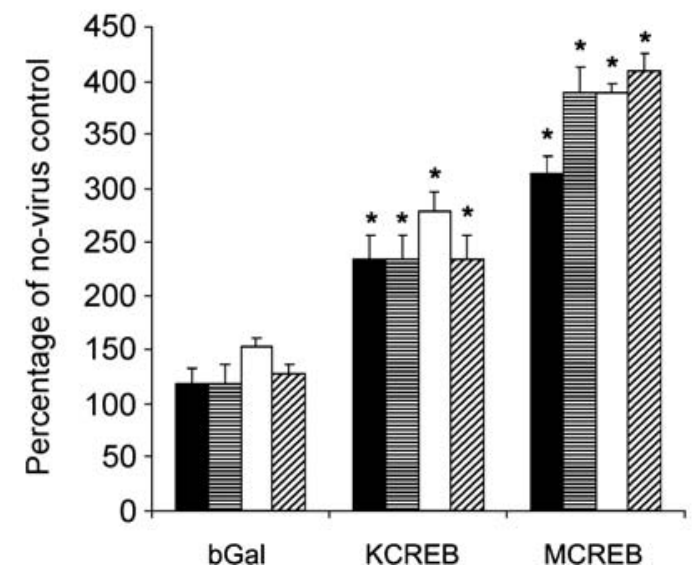

Fig. 2 Mutant forms of CREB activate caspase-9 and caspase-3 in human islets. Human islets were transduced with adenoviral beta galactosidase $(b G a l), \mathrm{KCREB}$ and MCREB at an MOI of 50 and 100 for $48 \mathrm{~h}$. Transduced islets along with no-virus control $(N V)$ were processed for immunoblot analysis (a) of active forms of caspase-9, $-8,-3$ and -7 and cleaved PARP. The blots were reprobed for beta (b) actin. b The bands were quantitated by scanning densitometry and corrected for beta actin. The results are means \pm SEM of three batches of islets. ${ }^{*} p<0.001$ vs bGal control. Black bars, active caspase-9; horizontal-hatched bars, active caspase-3; white bars, active caspase-7; diagonal-hatched bars, cleaved PARP transduced with adenoviral beta galactosidase was comparable to that in no-virus control. Both mutant forms of CREB increased activation of caspase-9, a marker for the mitochondrial pathway of apoptosis by two to fourfold (Fig. 2a). The active form of caspase- 8 was not detected, suggesting that the extrinsic pathway of apoptosis is not likely to play a significant role under these conditions. The active form of caspase-3, which is downstream of caspase-9, was also elevated after transduction of islets with adenoviral KCREB and MCREB. Quantitation of the bands in immunoblot analysis showed 2.4-fold and fourfold increases in active caspase- 3 with KCREB and MCREB (MOI 100) respectively (Fig. 2b). We also detected markers of executive and terminal phases of apoptosis. For example, activation of caspase-7, which is downstream of caspase-3, was observed. Accumulation of caspase-cleaved PARP was also detected. PARP, a nuclear enzyme that is involved in the recovery of cells after DNA damage, is cleaved by caspase- 9 and caspase-3. Next we examined the activities of the caspases as another measure of caspase activation. Substrates specific for caspase-9 (DEVD) and -3 (IETD) linked to $p$-nitroaniline were used. Both KCREB and MCREB increased the enzymic activities of caspase- 9 and -3 with the latter being more apoptotic than the former (Fig. 3a,b), a result that paralleled the changes in immunoblot analysis. Nuclear condensation as detected by DAPI staining was significantly $(p<0.001)$ greater in human islets transduced with adenoviral KCREB and MCREB when compared with beta galactosidase control (Fig. 3c). Taken together, these findings suggest that induction of the mitochondrial pathway of apoptosis in human islets occurs when CREB function is downregulated. Generally, we observed 10 to $15 \%$ of cell death by necrosis in our islet preparations. Further increases in necrosis were observed when islets were cultured for longer time periods, e.g. 4 to 7 days. The experiments described in this study were completed within 3 to 4 days after islet isolation. We observed the mechanism of cell death to be mainly apoptotic under conditions of CREB downregulation.

Dominant negative mutant forms of CREB activate caspase-9 and caspase-3 in beta cells Immunocytochemical analysis of islets using antibodies to active caspase- 9 and -3 demonstrated that the major changes induced by KCREB or MCREB occurred predominantly within beta cells (Figs. 4 and 5). The Cy3 (red) signal from active caspase-9 and -3 as quantitated by mean integrated fluorescence intensity of the images using Slide Book Application software showed a four to sixfold increase in beta cells by mutant forms of CREB. This is significantly more than the two to fourfold increase observed in immunoblot analysis of whole islets, probably due to the increased susceptibility of beta cells to injury. Another interesting aspect of the observation in 
Fig. 3 Mutant forms of CREB induce apoptosis in human islets. a, b Human islets were transduced with adenoviral beta galactosidase ( $b G a l)$, KCREB and MCREB at an MOI of 100 for $48 \mathrm{~h}$. The activities of caspase-9 (a) and caspase-3 (b) were determined using kits. The results are means \pm SEM of three batches of islets. $* p<0.001$ vs bGal control. $N V$ no-virus. $\mathbf{c}$ A portion of the treated islets was embedded in OCT and $7 \mu \mathrm{m}$ sections were made. The sections were stained for nuclei with DAPI and condensed nuclei were counted

\section{a}

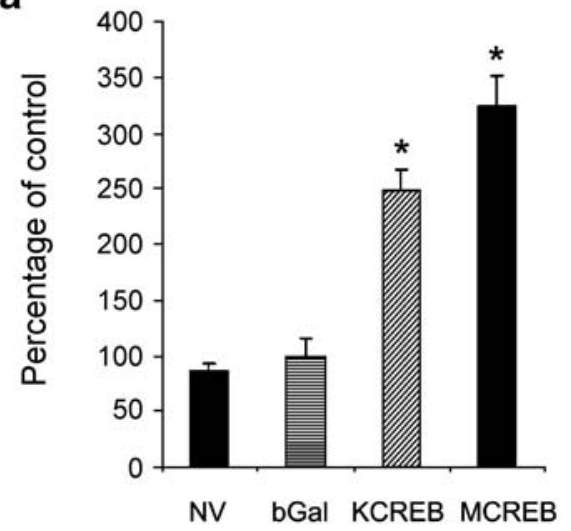

b

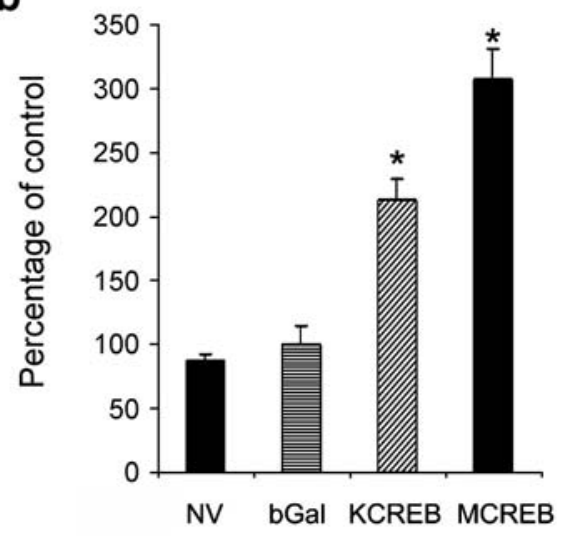

C
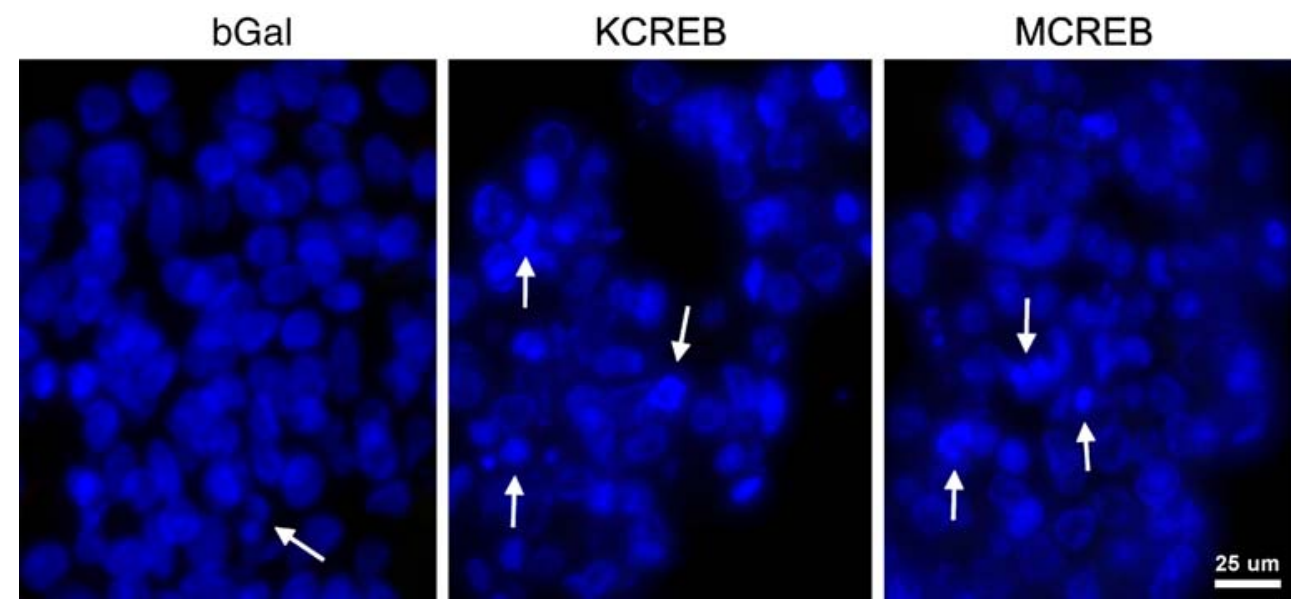

these experiments is that the majority of insulin-positive cells showed activation of caspases although we had indicated that transduction efficiency was at a maximum of $55 \%$. A possible explanation is that apoptosis induced in transduced beta cells could have an overall impact on the beta cell population of islets.

CREB downregulation potentiates cytokine-induced apoptosis in human islets Activation of caspase-9 and caspase-3 by cytokines $(4 \mathrm{ng} / \mathrm{ml}$ of IL- $1 \beta+20 \mathrm{ng} / \mathrm{ml}$ of TNF- $\alpha+$ $20 \mathrm{ng} / \mathrm{ml}$ of IFN- $\gamma$ ) in human islets was further potentiated $(p<0.001)$ by twofold when transduced with MCREB (MOI 50) as shown by the immunoblot analysis (Electronic supplementary material [ESM] text, supplementary Fig. 1).

Exendin-4 and betacellulin decrease cytokine-induced downregulation of CREB function and apoptosis To determine if activators of CREB could reduce cytokine-induced apoptosis, we used two beta cell-specific growth factors, exendin- 4 and BTC. Our preliminary studies showed that these two growth factors are less effective when used alone and therefore we used a combination of these two. They activated CREB through multiple and largely independent signalling pathways and showed additive effects in raising the active phosphorylated form of CREB (results not shown). When human islets were preincubated for $24 \mathrm{~h}$ with a combination of exendin-4 $(100 \mathrm{ng} / \mathrm{ml})$ and BTC $(10 \mathrm{nmol} / \mathrm{l})$ prior to exposure to cytokines, the number of TUNEL-positive beta cells in islets decreased significantly $(p<0.001$; Fig. 6a). TUNEL-positive cells among cells stained for insulin were counted in multiple fields from nonadjacent sections of embedded islets. The percentage of TUNEL-positive cells was $11.4 \pm 1.8$ and $3.6 \pm 0.8$ in cells incubated in the absence or presence of growth factors, respectively. When the islets were exposed to a mixture of cytokines, the percentage of TUNEL-positive cells increased to $32.7 \pm 4.8$, which was reduced by $60 \%(p<$ $0.001)$ after preincubation with exendin- 4 and BTC. These observations suggest that apoptosis in beta cells of isolated islets is significantly reduced under basal as well as cytokine-treated conditions by a combination of growth factors that activate CREB. Next, we also measured antiapoptotic markers in these islets. Decreases in phosphorylated active forms of AKT (Fig. 6b), one of the upstream 


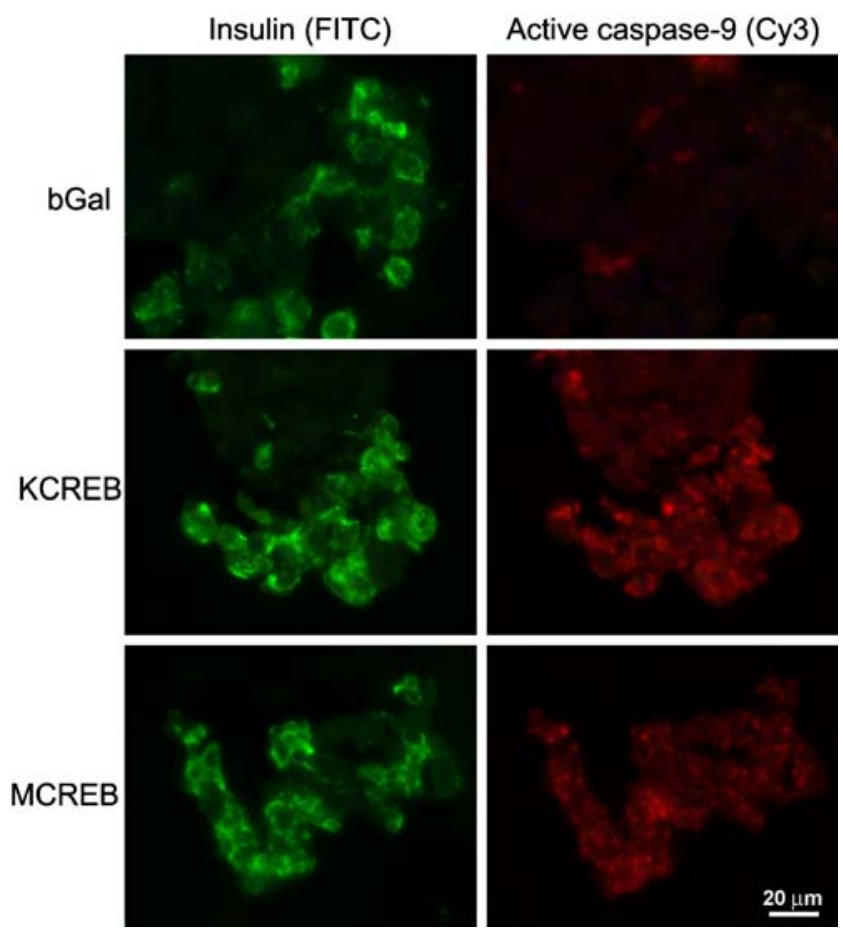

Fig. 4 Dominant negative mutant forms of CREB activate caspase-9 in beta cells of human islets. Human islets from three different batches were transduced (MOI 100) with recombinant adenoviruses encoding control beta galactosidase $(b G a l)$ or mutant forms of CREB (KCREB or MCREB) for $48 \mathrm{~h}$. The treated islets were embedded in OCT and $7 \mu \mathrm{m}$ sections were made, on which immunocytochemical analysis of islets was carried out. After fixing and permeabilisation, sections were exposed to guinea pig anti-insulin antibody and rabbit active caspase-9 antibody. After washing, islets were stained with appropriate secondary antibodies linked to FITC (insulin) and Cy3 (caspase-9). Sections were mounted with mounting medium for fluorescent microscopy. A representative image is provided

kinases of CREB and phosphorylation of CREB (Fig. 6c), were restored to the levels in control islets not exposed to cytokines. It should be mentioned here that the increases in phosphorylated forms of AKT and CREB in growth factor-treated islets above the basal condition were moderate $(42-50 \% ; p<0.05)$, since treatment with exendin-4 and BTC was for $24 \mathrm{~h}$. Activation of signalling by growth factors in general reaches a maximum at 10 to $15 \mathrm{~min}$. The decreases in these signals induced by cytokines over $24 \mathrm{~h}$ were significantly restored by growth factors (two to threefold; $p<0.001$ ). Next, the production of anti-apoptotic protein BCL2, which is positively regulated by CREB, was also maintained in cytokine-treated islets at control levels (Fig. 6d). These actions of exendin-4 and BTC are likely to play a role in their cytoprotective action.

Anti-apoptotic effects of exendin-4 and BTC in human islets are partially blocked by a mutant form of CREB To determine if CREB plays a role in mediating the effects

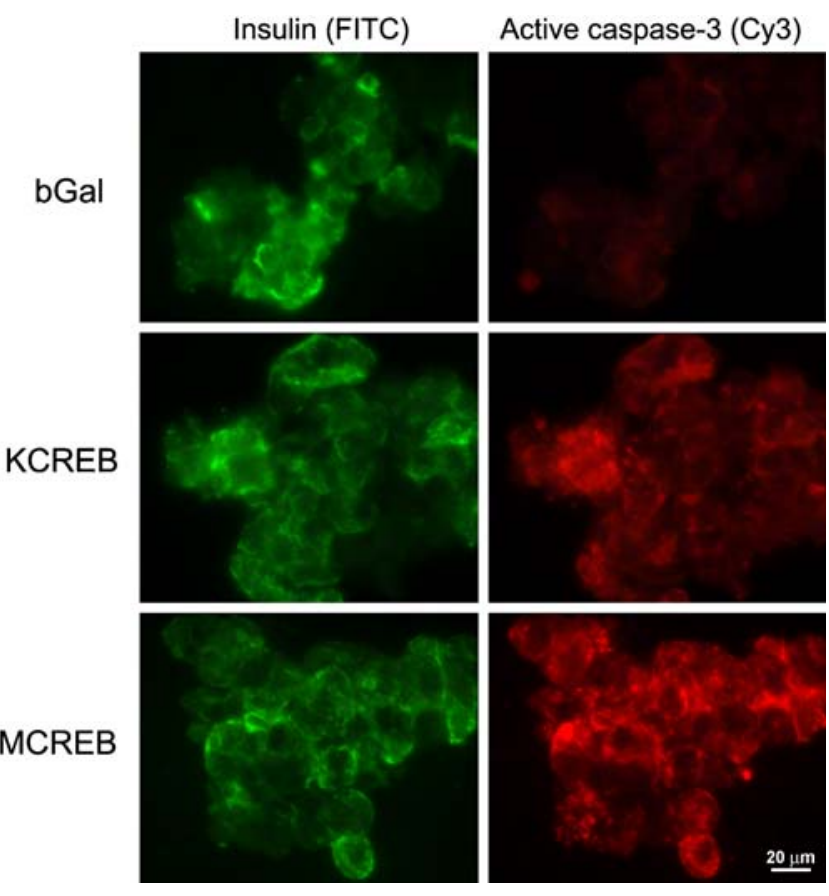

Fig. 5 Dominant negative mutant forms of CREB activate caspase-3 in beta cells of human islets. Human islets transduced with adenoviral beta galactosidase ( $\mathrm{bGal}$ ) or KCREB or MCREB (MOI 100) for $48 \mathrm{~h}$ were embedded in OCT and frozen. Sections ( $7 \mu \mathrm{m}$ thickness) were permeabilised and incubated in the presence of guinea pig anti insulin antibody and rabbit active caspase- 3 antibody. After washing, islets were stained with secondary antibodies linked to FITC (insulin) and Cy3 (caspase-3). Sections were mounted with mounting medium for fluorescent microscopy. Representative images from immunofluorescent analysis of three batches of islets are provided

of exendin-4 and BTC, we examined the effects of growth factors on activation of caspase- 3 in human islets transduced with MCREB. First we examined the effect of transduction with MCREB on growth factor-mediated CREB phosphorylation, an important step needed for its activation at the peak time point of 10 min (Fig. 7a). This mutant decreased the level of phosphorylated CREB in islets exposed to growth factors by $75 \%$ ( $p<0.001$; Fig. 7b). Next, we observed that growth factors exendin- 4 and BTC decreased $(p<0.001)$ cytokine-mediated activation of caspase-3 in islets as shown by the assay of enzyme activities (Fig. 7c). However, the anti-apoptotic effect of growth factors was partially and significantly lost when the CREB function was downregulated by transduction with MCREB. For example, caspase- 3 activity in islets producing MCREB and treated with cytokines and growth factors was $55 \%$ ( $p<$ $0.01)$ more than in the corresponding beta galactosidase control but $21 \%(p<0.05)$ less than in cytokine-treated islets. The probable reason could be that adenoviral transduction of MCREB was achieved only in $\sim 50 \%$ of islets, whereas the growth factors exert their action in all islets. 


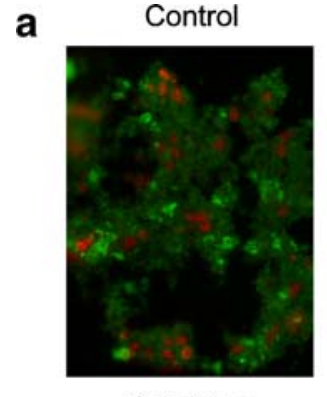

Cytokines

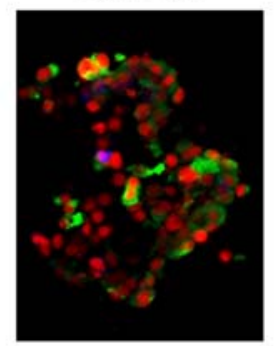

C PCREB
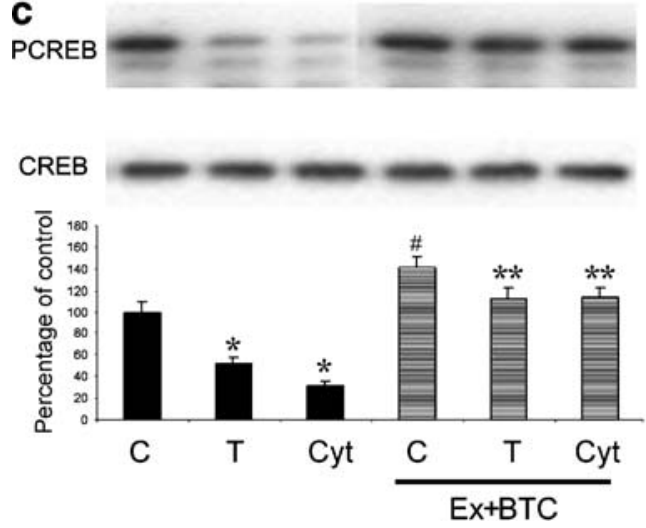

Fig. 6 Activators of CREB exert anti-apoptotic effects in human islets. a Human islets were exposed to a mixture of cytokines ( $4 \mathrm{ng} / \mathrm{ml}$ of IL$1 \beta, 20 \mathrm{ng} / \mathrm{ml}$ of TNF- $\alpha$ and $20 \mathrm{ng} / \mathrm{ml}$ of IFN- $\gamma$ ) and/or a combination of exendin-4 $(E x ; 100 \mathrm{ng} / \mathrm{ml})$ and BTC $(10 \mathrm{nmol} / \mathrm{l})$ for $24 \mathrm{~h}$. The treated islets were embedded in OCT and frozen. Sections ( $7 \mu \mathrm{m}$ thickness) were TUNEL-stained (red) using a cell death detection kit, stained for insulin with FITC (green) and analysed by fluorescence microscopy. A representative image for each treatment is provided. TUNEL-positive beta cells were counted in multiple fields of four nonadjacent sections. The results are means \pm SEM of three batches of islets. TUNEL-positive cells: control, $11.4 \pm 1.8 ; \mathrm{Ex}+\mathrm{BTC}, 3.6 \pm 0.8 \quad(p<0.001$ vs control); cytokines, $32.7 \pm 4.8$ ( $p<0.001$ vs control); cytokines + Ex + BTC, $13.1 \pm$ 1.4 ( $p<0.001$ when compared with cytokine-treated islets). b-d Human

\section{Discussion}

Reducing apoptosis in human islets during storage and after transplantation is potentially an important strategy to improve transplantation outcomes. CREB is a transcription factor with critical survival gene targets and loss of CREB function leads to mouse beta cell apoptosis in vitro and in vivo $[13,17,18]$. In this study, we demonstrate that when CREB-mediated transcription is downregulated by domi- b
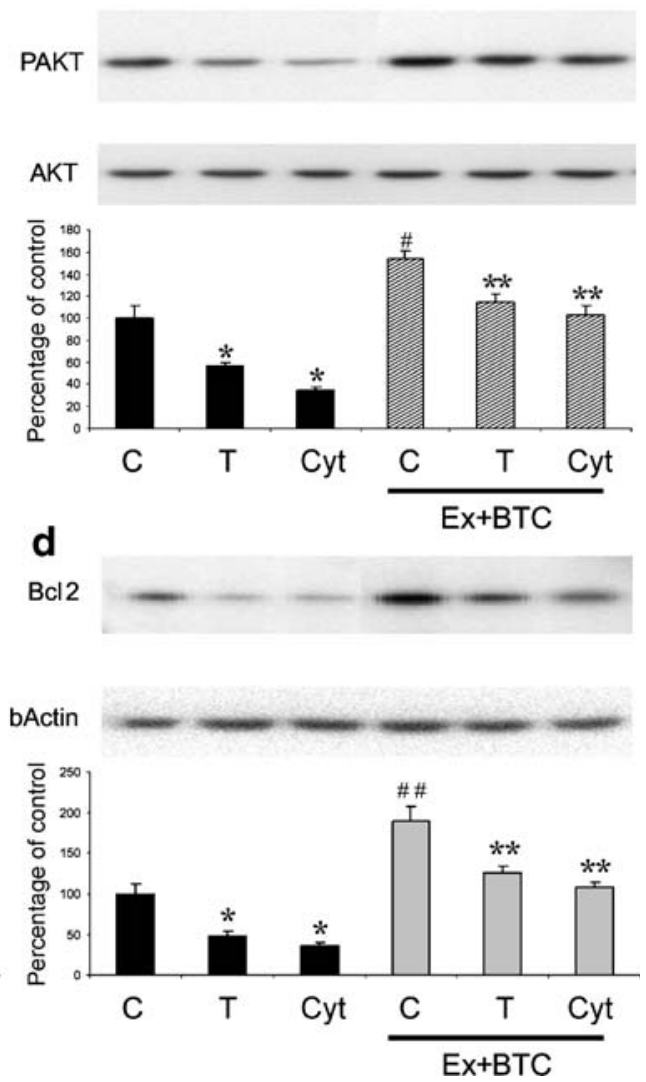

islets from three different batches were exposed to TNF- $\alpha(T ; 50 \mathrm{ng} / \mathrm{ml})$ or a mixture of cytokines $(C y t ; 4 \mathrm{ng} / \mathrm{ml}$ of IL- $1 \beta, 20 \mathrm{ng} / \mathrm{ml}$ of TNF- $\alpha$ and $20 \mathrm{ng} / \mathrm{ml}$ of IFN- $\gamma$ ) in the absence and presence of a combination of exendin-4 $(100 \mathrm{ng} / \mathrm{ml})$ and BTC $(10 \mathrm{nmol} / \mathrm{l})$ for $24 \mathrm{~h}$. After washing the islets in cold PBS, they were lysed with cell lysis buffer and the protein content was determined. Samples with equal protein content were immunoblotted for phospho (P) AKT, AKT, phospho (P) CREB, CREB, BCL2 and beta actin (bActin). Representative blots are presented. The band intensities were quantitated for PAKT/AKT (b), PCREB/CREB (c) and BCL2/bActin (d) by scanning densitometry. The results are means \pm SEM of three different batches of islets. ${ }^{*} p<0.001,{ }^{\#} p<0.05$ and ${ }^{\# \#} p<$ 0.01 vs untreated islets; ${ }^{* *} p<0.001$ when compared with corresponding cytokine treatment without growth factors

nant negative mutant forms of CREB (MCREB and KCREB), the apoptotic profile of human islets in the transplantation setting is modified. Furthermore, we observed that the anti-apoptotic effects of the growth factors exendin-4 (an analogue of glucagon-like peptide-1) and BTC are reduced in human islets when CREB function is compromised. Taken together, these observations suggest that maintenance of CREB-mediated transcription could be cytoprotective to human islets. 
a

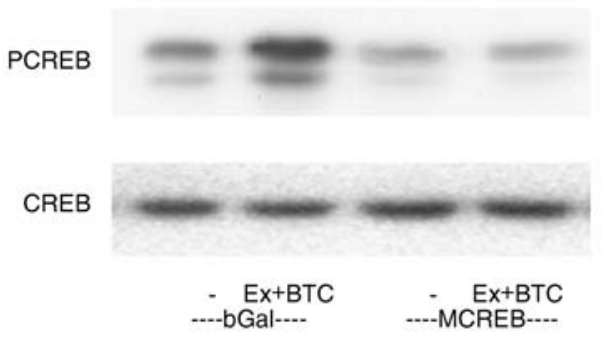

b

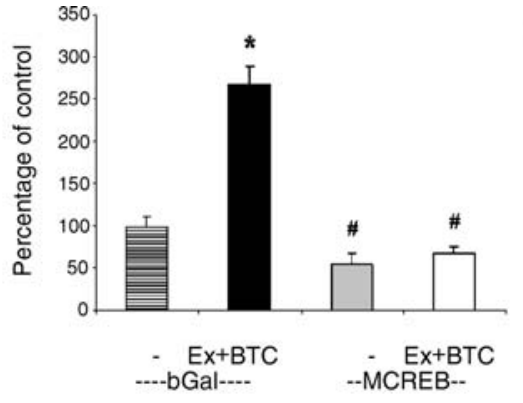

C

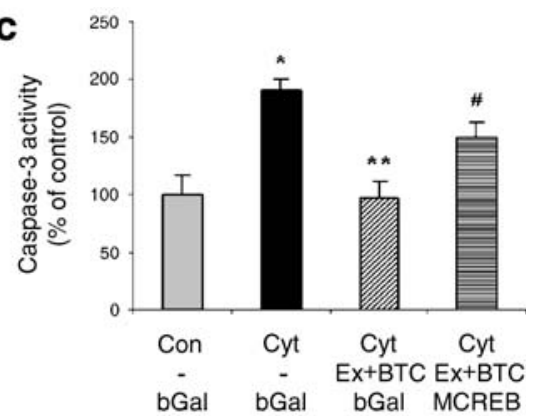

Fig. 7 Dominant negative MCREB partially blocks growth factormediated anti-apoptotic effects in human islets a Human islets were transduced with adenoviral beta galactosidase ( $b G a l)$ or MCREB. After $24 \mathrm{~h}$, they were exposed to exendin-4 $(E x ; 100 \mathrm{ng} / \mathrm{ml})$ and BTC $(10 \mathrm{nmol} / \mathrm{l})$ for $15 \mathrm{~min}$. The treated islets were processed for immunoblot analysis of PCREB and CREB. A representative blot is presented. $\mathbf{b}$ The intensity of bands was measured (see "Materials and methods"). The results shown are means $\pm \mathrm{SEM}$ of three different batches of islets. ${ }^{*} p<$ 0.001 vs bGal control; ${ }^{\#} p<0.001$ vs corresponding bGal control in the absence and presence of growth factors. $\mathbf{c}$ Human islets were transduced with adenoviral bGal or MCREB. After $24 \mathrm{~h}$, they were exposed to a mixture of cytokines $(C y t ; 4 \mathrm{ng} / \mathrm{ml}$ of IL-1 $\beta, 20 \mathrm{ng} / \mathrm{ml}$ of TNF- $\alpha$ and $20 \mathrm{ng} / \mathrm{ml}$ of IFN- $\gamma)$ and/or a combination of exendin-4 $(100 \mathrm{ng} / \mathrm{ml})$ and BTC $(10 \mathrm{nmol} / \mathrm{l})$ as indicated for another $24 \mathrm{~h}$. The treated islets were processed for caspase- 3 assay. The results are means \pm SEM of three independent batches of islets. ${ }^{*} p<0.001 \mathrm{vs} \mathrm{bGal} \mathrm{control;}{ }^{*} p<0.001 \mathrm{vs}$ bGal+cytokines; ${ }^{\#} p<0.01$ vs bGal+Cytokines + Ex + BTC and $p<0.05$ vs bGal+cytokines
To understand the pathway of apoptosis induced by CREB downregulation, we examined a panel of apoptotic markers (Fig. 2). First, we saw activation of caspase-9, a marker for the activation of the intrinsic mitochondrial pathway, but not of caspase-8, a marker for the extrinsic pathway. The mitochondrial pathway of apoptosis is regulated by the BCL2 family of proteins, which includes anti-apoptotic BCL2, BCL-XL and the pro-apoptotic proteins $\mathrm{BAD}$ and BAX. The integrity of the mitochondrial membrane is dependent on the balance between these two groups of proteins [23]. In the present study, there was also evidence for the later committed stages of apoptosis as shown by an increase in active forms of caspase- 3 and caspase-7. Caspase-7 plays an important role in cell death, causing cleavage of important cellular regulatory proteins. Furthermore, we detected significant amounts of cleaved PARP, a substrate for caspase-3 and caspase-7. Cells with condensed nuclei, another marker of apoptosis, were significantly more frequent in islets transduced with adenoviral KCREB and MCREB when compared with control (Fig. 3). Thus observations from this detailed examination of apoptotic pathways provide new information regarding beta cell death under conditions of CREB downregulation.

CREB regulates the expression of several genes involved in cell growth, function and survival $[24,25]$. Although CREB-mediated gene expression has been characterised in neurons, limited information is available regarding its role in beta cell survival [26-28]. The promoter region of the $c-I A P 2$ gene, which belongs to the family of inhibitors of apoptosis, contains CRE sites [29]. IRS2 an important mediator of growth factor action is also a CREB-dependent gene [17]. Inada et al. [18] demonstrated that transgenic mice with beta cell-targeted expression of inducible cyclic
AMP early repressor, which interferes with CREB function, is characterised by early diabetes due to impaired beta cell proliferation. Transgenic mice expressing ACREB, a dominant negative form of CREB, develop diabetes as a result of beta cell apoptosis [17]. We and others have shown that CREB plays a critical role in inducing the antiapoptotic gene $B c l 2$ [15, 20, 30]. Therefore, downregulation of CREB could be expected to induce apoptosis by the mitochondrial pathway as observed in this study. The role of CREB in cell survival has been demonstrated in other cell types as well by in vivo and in vitro studies [31-34].

Next we examined the role of CREB in mediating the anti-apoptotic action of growth factors. Treatment of isolated human islets with growth factors for improving beta cell survival has been previously suggested as an important strategy for improving islet survival [35]. We suggest that CREB needs to be an important component of this strategy. Even after transplantation, when CREB function is reduced, growth promoting effects of endogenous growth factors are likely to be reduced significantly and it can lead to graft failure. In this study, exendin-4 and BTC together increased CREB phosphorylation/activation, restored BCL2 production and decreased apoptosis in cytokine-treated islets (Fig. 6). Activation of CREB seems to be needed for the anti-apoptotic effects of exendin-4 and BTC, since overexpression of the gene encoding MCREB, which interferes with CREB phosphorylation, reduced significantly the cytoprotective effects of these two growth factors (Fig. 7). We have previously demonstrated that IGF-I induces the expression of $B c l 2$, by activating CREB through multiple signalling pathways in $\mathrm{PC} 12$ cells, a neuronal cell line $[15,20]$. Therefore, treating human islets in vitro with growth factors for improving islet survival needs to be done in conjunction with other agents such as 
antioxidants that preserve CREB function [36]. Bottino et al. [37] have demonstrated the beneficial effects of a novel antioxidant compound in improving islet survival. We have previously demonstrated that antioxidants restore CREBmediated transcription $[36,38]$.

Although islet transplantation is a promising therapy, the potential demand for such a treatment greatly outstrips the supply of human islets from cadaveric donors. In addition to multiple approaches taken to increase the supply of islets, there is a need to limit islet loss during isolation and following transplantation, ensuring that this precious resource is efficiently utilised. Findings from our current study suggest that preservation of CREB function could lead to improvement in beta cell survival in transplanted islets.

Acknowledgements This work was supported by grants from the Juvenile Diabetes Research Foundation (5-2005-1104 to S. Pugazhenthi and 1-2002-293 to J. E.-B. Reusch), American Diabetes Research (1-06-JF-40 to S. Pugazhenthi), National Institutes of Health (RO1DK033470 to R. G. Gill) and by a Diabetes and Endocrinology Research Center grant (P30 DK057516 to J. C. Hutton).

Duality of interest The authors declare that they have no duality of interest.

\section{References}

1. Shapiro AM, Lakey JR, Ryan EA et al (2000) Islet transplantation in seven patients with type 1 diabetes mellitus using a glucocorticoid-free immunosuppressive regimen. N Engl J Med 343:230238

2. Emamaullee JA, Shapiro AM (2006) Interventional strategies to prevent beta-cell apoptosis in islet transplantation. Diabetes 55:1907-1914

3. Paraskevas S, Maysinger D, Wang R, Duguid TP, Rosenberg L (2000) Cell loss in isolated human islets occurs by apoptosis. Pancreas 20:270-276

4. Balamurugan AN, He J, Guo F et al (2005) Harmful delayed effects of exogenous isolation enzymes on isolated human islets: relevance to clinical transplantation. Am J Transplant 5:2671-2681

5. Johansson U, Olsson A, Gabrielsson S, Nilsson B, Korsgren O (2003) Inflammatory mediators expressed in human islets of Langerhans: implications for islet transplantation. Biochem Biophys Res Commun 308:474-479

6. Corbett JA, Kwon G, Marino MH et al (1996) Tyrosine kinase inhibitors prevent cytokine-induced expression of iNOS and COX-2 by human islets. Am J Physiol 270:C1581-C1587

7. Lenzen S, Drinkgern J, Tiedge M (1996) Low antioxidant enzyme gene expression in pancreatic islets compared with various mouse tissues. Free Radic Biol Med 20:463-466

8. Bertera S, Crawford ML, Alexander AM et al (2003) Gene transfer of manganese superoxide dismutase extends islet graft function in a mouse model of autoimmune diabetes. Diabetes 52:387-393

9. Contreras JL, Bilbao G, Smyth CA et al (2001) Cytoprotection of pancreatic islets before and soon after transplantation by gene transfer of the anti-apoptotic Bcl-2 gene. Transplantation $71: 1015-1023$
10. Deng S, Vatamaniuk M, Lian MM et al (2003) Insulin gene transfer enhances the function of human islet grafts. Diabetologia 46:386-393

11. Klein D, Ribeiro MM, Mendoza V et al (2004) Delivery of $\mathrm{Bcl}-\mathrm{XL}$ or its $\mathrm{BH} 4$ domain by protein transduction inhibits apoptosis in human islets. Biochem Biophys Res Commun 323:473-478

12. Emamaullee JA, Rajotte RV, Liston P et al (2005) XIAP overexpression in human islets prevents early posttransplant apoptosis and reduces the islet mass needed to treat diabetes. Diabetes 54:2541-2548

13. Jambal P, Masterson S, Nesterova A et al (2003) Cytokinemediated downregulation of the transcription factor CREB in pancreatic beta-cells. J Biol Chem 278:23055-23065

14. Oetjen E, Grapentin D, Blume R et al (2003) Regulation of human insulin gene transcription by the immunosuppressive drugs cyclosporin $\mathrm{A}$ and tacrolimus at concentrations that inhibit calcineurin activity and involving the transcription factor CREB. Naunyn Schmiedebergs Arch Pharmacol 367:227-236

15. Pugazhenthi S, Miller E, Sable C et al (1999) Insulin-like growth factor-I induces bcl-2 promoter through the transcription factor cAMP-response element binding protein. J Biol Chem 274:27529-27535

16. Finkbeiner S, Tavazoie SF, Maloratsky A, Jacobs KM, Harris KM, Greenberg ME (1997) CREB: a major mediator of neuronal neurotrophin responses. Neuron 19:1031-1047

17. Jhala US, Canettieri G, Screaton RA et al (2003) cAMP promotes pancreatic beta-cell survival via CREB-mediated induction of IRS2. Genes Dev 17:1575-1580

18. Inada A, Hamamoto Y, Tsuura Y et al (2004) Overexpression of inducible cyclic AMP early repressor inhibits transactivation of genes and cell proliferation in pancreatic beta cells. Mol Cell Biol 24:2831-2841

19. Gomez-Foix A, Coats W, Baque S, Alam T, Gerald R, Newgard C (1992) Adenovirus-mediated transfer of the muscle glycogen phosphorylase gene into hepatocytes confers altered regulation of glycogen metabolism. J Biol Chem 267:25129-25134

20. Pugazhenthi S, Nesterova A, Sable C et al (2000) Akt/protein kinase $\mathrm{B}$ up-regulates $\mathrm{Bcl}-2$ expression through cAMP-response element-binding protein. J Biol Chem 275:10761-10766

21. Jones N, Shenk T (1978) Isolation of deletion and substitution mutants of adenovirus type 5. Cell 13:181-188

22. Bradford MM (1976) A rapid and sensitive method for the quantitation of microgram quantities of protein utilizing the principles of protein-dye binding. Anal Biochem 72:248-254

23. Merry DE, Korsmeyer SJ (1997) Bcl-2 gene family in the nervous system. Annu Rev Neurosci 20:245-267

24. Montminy M (1997) Transcriptional regulation by cyclic AMP. Annu Rev Biochem 66:807-822

25. Shaywitz AJ, Greenberg ME (1999) CREB: a stimulus-induced transcription factor activated by a diverse array of extracellular signals. Annu Rev Biochem 68:821-861

26. Eggers A, Siemann G, Blume R, Knepel W (1998) Gene-specific transcriptional activity of the insulin cAMP-responsive element is conferred by NF-Y in combination with cAMP response element binding protein. J Biol Chem 273:18499-18508

27. Ban N, Yamada Y, Someya Y et al (2000) Activating transcription factor-2 is a positive regulator in CaM kinase IV-induced human insulin gene expression. Diabetes 49:1142-1148

28. Susini S, Haasteren GV, Li S, Prentki M, Schlegel W (2000) Essentiality of intron control in the induction of c-fos by glucose and glucoincretin peptides in INS-1 beta-cells. FASEB J 14:128136

29. Nishihara H, Kizaka-Kondoh S, Insel PA, Eckmann L (2003) Inhibition of apoptosis in normal and transformed intestinal epithelial cells by cAMP through induction of inhibitor of 
apoptosis protein (IAP)-2. Proc Natl Acad Sci U S A 100:89218926

30. Wilson BE, Mochon E, Boxer LM (1996) Induction of bcl-2 expression by phosphorylated CREB proteins during B-cell activation and rescue from apoptosis. Mol Cell Biol 16:55465556

31. Yang YM, Dolan LR, Ronai Z (1996) Expression of dominant negative CREB reduces resistance to radiation of human melanoma cells. Oncogene 12:2223-2233

32. Jean D, Harbison M, McConkey DJ, Ronai Z, Bar-Eli M (1998) CREB and its associated proteins act as survival factors for human melanoma cells. J Biol Chem 273:24884-24890

33. Fentzke RC, Korcarz CE, Lang RM, Lin H, Leiden JM (1998) Dilated cardiomyopathy in transgenic mice expressing a dominant-negative CREB transcription factor in the heart. J Clin Invest 101:2415-2426
34. Struthers RS, Vale WW, Arias C, Sawchenko PE, Montminy MR (1991) Somatotroph hypoplasia and dwarfism in transgenic mice expressing a non-phosphorylatable CREB mutant. Nature 350:622-624

35. Garcia-Ocana A, Vasavada RC, Takane KK, Cebrian A, LopezTalavera JC, Stewart AF (2001) Using beta-cell growth factors to enhance human pancreatic islet transplantation. J Clin Endocrinol Metab 86:984-988

36. Pugazhenthi S, Nesterova A, Jambal P et al (2003) Oxidative stress-mediated down-regulation of bcl-2 promoter in hippocampal neurons. J Neurochem 84:982-996

37. Bottino R, Balamurugan AN, Tse $\mathrm{H}$ et al (2004) Response of human islets to isolation stress and the effect of antioxidant treatment. Diabetes 53:2559-2568

38. Haskins K, Bradley B, Powers K et al (2003) Oxidative stress in type 1 diabetes. Ann N Y Acad Sci 1005:43-54 